\title{
Characterization of Surface Properties, Osteoblast Cell Culture in Vitro and Processing with Flow-Viscosity of Ni-Free Ti-Based Bulk Metallic Glass for Biomaterials*
}

\author{
Jeong-Jung OAK**, Gi-Wook HWANG***, Yong-Ha PARK****, \\ Hisamichi KIMURA**, Seog-Young YOON**** and Akihisa INOUE** \\ ${ }^{* *}$ Institute for Materials Research, Tohoku University, 2-1-1Katahira, Aoba-ku, Sendai, 980-8577, Japan \\ E-mail:ojj69@imr.tohoku.ac.jp \\ *** Laboratory of Molecular and Biochemical Toxicology, Graduate School of Pharmaceutical Sciences, \\ Tohoku University, 6-3, Aramaki Aoba, Aoba-ku, Sendai, 980-8578, Japan \\ **** School of Materials Science \& Engineering, Pusan National University, 30 Jangjeon-dong, \\ Geumjeong-gu, Busan, 609-735, South Korea
}

\begin{abstract}
Ni-free type Ti-based metallic glass evaluated in this study has imposing performances for biomaterials that is based on high bulk forming ability (BFA) for implantable materials, superior specific strength, low Young's modulus as hard tissue replacements and excellent workability. Especially, surface characteristics of Ti-based bulk metallic glass for corrosion resistance exhibit a high potential for application to be used as dental implants in the oral cavity. We also made an examination of chemical stability for human cell test with osteoblasts (SaOS2) in vitro. Results of the good biocompatibility and high glass forming ability evaluated in this study are expected to increase utility value for biomedical application
\end{abstract}

Key words: Ti Alloy, Bulk Metallic Glasses, Corrosion Resistance, Cell Culture, Implant Materials

\section{Introduction}

Recently, a number of metallic devices for biomaterials have been developed on around Ti-based alloys and are still going on now. Because of Ti as the used main solute produces a good biocompatibility by high corrosion resistance for human biochemical environment. Especially, most up-graded Ti-based alloys reveal distinguished mechanical performance, i.e. high strength, low elastic modulus and large plastic deformation. It has been reported that the greatest amount of bcc $\beta$ phase within alloy matrix contribute to these phenomena ${ }^{(1)}$. Meanwhile, the other peculiar metallic material is also reported by rapid solid solidification form liquid metal state. It is called by "amorphous alloys". They have an random atomic structure that exhibits good performance on mechanical strength and chemical properties ${ }^{(2)(3)(4)(5)}$. Especially, bulk metallic glasses (BMGs) are most upgraded amorphous metals with glassy properties as glass transition region before crystallization ${ }^{(6)}$. Workability by flow viscosity at supercooled liquid region and excellent bulk forming ability (BFA) of BMGs are also exclusive characteristics of metallic glasses. Ti- and Zr-based metallic glasses have been attempted to development for biomaterials which are 
called by Ni-free style BMGs and show good performance for biomedical implant application ${ }^{(7)(8)(9)}$. In case of increasing BFA in BMG, $\mathrm{Ni} \mathrm{Al}$ and $\mathrm{Be}$ are hired as essential elements in alloying which have a high potential is the origin for toxic. We have been reported $\mathrm{Ni}$-free type Ti-based $\mathrm{BMG}, \mathrm{Ti}_{45} \mathrm{Zr}_{10} \mathrm{Pd}_{10} \mathrm{Cu}_{31} \mathrm{Sn}_{4}$ alloy ${ }^{(7)}$, does not contain above potential toxic elements that is one of Ni-free based BMG series. The $\mathrm{Ti}_{45} \mathrm{Zr}_{10} \mathrm{Pd}_{10} \mathrm{Cu}_{31} \mathrm{Sn}_{4}$ metallic glassy rod was produced by copper mold casting exhibits good mechanical properties. In addition, the Ni-free Ti based BMG alloy has a high corrosion resistance and is passivated at the lower passive current density compared to those of pure Titanium and Ti-6Al-4V alloy in PBS (phosphate-buffered saline) and 1 mass $\%$ lactic acid at $310 \mathrm{~K}$. It seems to be that these properties have enough to satisfy primary stage of biocompatibility for medical metallic devices. In this study, we examined evidence of relationship between chemical properties from surface structure of Ni-free Ti-based BMG and biocompatibility for organic cells.

\section{Experimental procedure}

\subsection{Preparation of specimens}

Bulk metallic glass with a nominal composition of the $\mathrm{Ti}_{45} \mathrm{Zr}_{10} \mathrm{Pd}_{10} \mathrm{Cu}_{31} \mathrm{Sn}_{4}$ alloy was prepared by arc melting the mixture of pure metals in an argon atmosphere. Cylindrical rod samples with a diameter of $2.5 \sim 3.0 \mathrm{~mm}$ and length of $50 \mathrm{~mm}$ were produced by copper mold casting technique in an argon atmosphere. The structure of as-cast rods was examined by X-ray diffraction (Rint 2000; Rigaku, Tokyo, Japan) using $\mathrm{Cu} \mathrm{K \alpha}$ radiation at $40 \mathrm{kV}$ and $30 \mathrm{~mA}$. Prior to tests, the samples with a diameter of $2.5 \mathrm{~mm}$ for surface analysis were cute length of $5 \mathrm{~mm}$ and the sample with a diameter of $3.0 \mathrm{~mm}$ for cell culture in human osteoblast were cute length of $2 \mathrm{~mm}$, mechanically polished with silicon carbide emery paper up to grit 2000, ultrasonically degreased in acetone, washed in distilled water, dried in air, and then exposed to air for $24 \mathrm{~h}$ at room temperature for good reproducibility.

\subsection{Surface analysis}

X-ray photoelectron spectroscopy (XPS) measurements for surface analysis of the specimens before and after immersion in solutions were performed using an SSI SSX-100 photoelectron spectrometer with monochromatized Al Ka excitation $(h v=1486.6 \mathrm{eV})$. The specimens were immersed in electrolytes of 1 mass\% lactic acid and PBS (-) aqueous solutions (table 1) open to air at $310 \mathrm{~K}$. The compositions of the surface film and the underlying alloy surface were quantitatively determined with the previously proposed method using the integrated intensities of photoelectrons under the assumption of a three-layer model of an outermost contaminant hydrocarbon layer of uniform thickness, a surface film of uniform thickness and an underlying alloy surface of infinite thickness as regards X-ray- photoelectrons.

\subsection{Cytotoxic estimation}

Biocompatibility for cytotoxicity of Ti-based BMG was evaluated by cell experiment in vitro. Human osteoblasts (SaOS2) were used at population numbers between 6 and 12 without further characterization. Osteoblasts were cultured in Dulbecco's Modified Eagle Medium (DMEM) supplemented with $10 \%$ fetal bovine serum (FBS) and 1\% penicillin/streptomycin under standard cell culture conditions, i.e., a humidified, 5\% $\mathrm{CO}_{2} / 95 \%$ air environment at $310 \mathrm{~K}$. Osteoblasts of passages 3-6 were used for the experiments. Cells were plated in 12 -well plates at a concentration of $2 \times 10^{5}$ cells/ well. Added subject metals after the incubated for $24 \mathrm{~h}$. In this test, all subject metals, which have references also used commercially titanium alloy (Ti-6Al-V) and Ti-45Ni alloy particles of cylindrical rod with diameter of $3 \mathrm{~mm}$, were observed for 8 days and exchanged fresh medium every 2 days for 8 days. Cytotoxic-metabolite elution of subject metals in medium 
culture of human osteoblast were observed degree of cell death form releasing of ion radical by microscope $(200 \mathrm{X})$ / CCD camera.

\subsection{Workability evaluation}

Nominal composition of $\mathrm{Ti}_{45} \mathrm{Zr}_{10} \mathrm{Pd}_{10} \mathrm{Cu}_{31} \mathrm{Sn}_{4}$ (in at. \%) metallic glassy powders were prepared by a high-pressure gas atomizer. The size of powder for consolidation used is less than $125 \mu \mathrm{m}$ in globular shape. And cylindrical rod samples with a length of $5 \mathrm{~mm} \sim$ and a diameter of $12 \mathrm{~mm}$ for above composites were prepared by SPS (Sumitomo Coal Mining Co., LTD, Japan) technique with WC punches in a vacuum condition for evidence of bulk forming ability. Sintering temperature was controlled automatically by the inserted thermocouple in die with a diameter $12 \mathrm{~mm}$. For detecting primary phase of powder and SPSed sample, these structural properties of specimens were examined by X-ray diffraction (XRD: Rigaku Rint 2000) using $\mathrm{Cu} \mathrm{K} \alpha$ radiation at $40 \mathrm{kv}, 30 \mathrm{~mA}$. Consolidation was carried out SPS at the boundary between flow-viscosity region and under the crystallization for glassy sate, during $40 \mathrm{~K} / \mathrm{s}$ with pressure for $600 \mathrm{MPa}$.

\section{Results and discussion}

Figure 1 shows the X-ray diffraction patterns of the as-cast cylindrical rod specimens

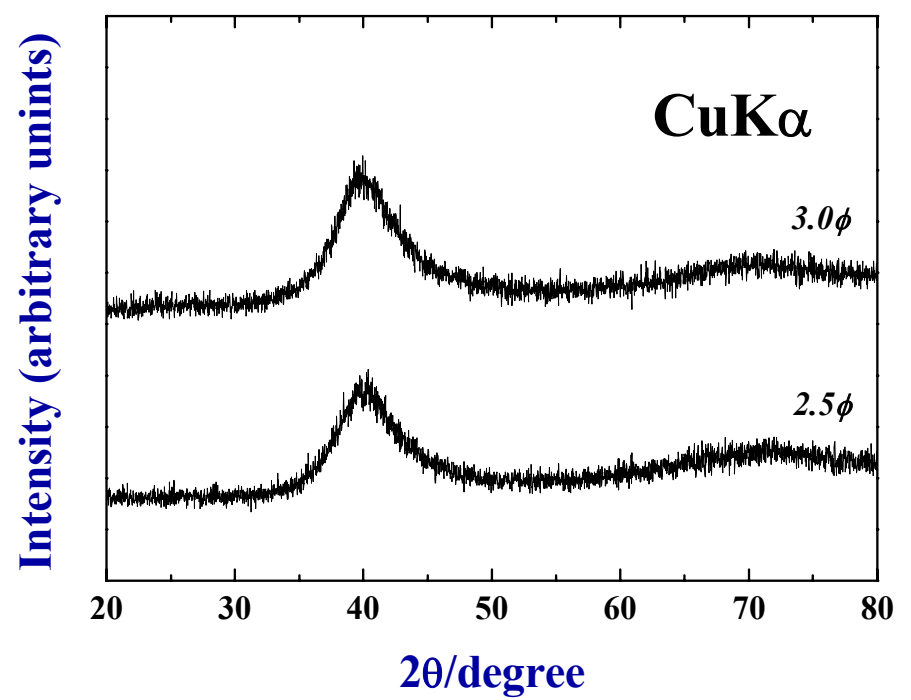

Fig. 1. X-ray diffraction (XRD) patterns taken from the cross-sections of $\mathrm{Ti}_{45} \mathrm{Zr}_{10} \mathrm{Pd}_{10} \mathrm{Cu}_{31} \mathrm{Sn}_{4}$ glassy rods with a diameter of 2.5 and $3 \mathrm{~mm}$

(2.5 and $3 \mathrm{~mm}$ in diameter) of the $\mathrm{Ti}_{45} \mathrm{Zr}_{10} \mathrm{Pd}_{10} \mathrm{Cu}_{31} \mathrm{Sn}_{4}$. The rod samples show broad diffraction peaks typical for the amorphous phase which indicates their high glass forming ability.

Figure 2 illustrates laminate structures in surface of $\mathrm{Ti}_{45} \mathrm{Zr}_{10} \mathrm{Pd}_{10} \mathrm{Cu}_{31} \mathrm{Sn}_{4}$ metallic glass form XPS analysis. It explains the composition ratios of glassy alloy and the oxidation states in the surface film as well as metallic states of preoxidation process in the underlying surface tissue. These layer structures were generated in the samples immersed in SBF solutions after mechanical polishing. Irradiated output energy with integrated intensities were used to detect the regional characterization, i.e. the composition of the surface film, the composition of the underlying alloy surface and the thickness of surface film which were determined by quantitative analytical method ${ }^{(10)(11)}$. Figure 3 makes clear surface conditions of specimen that the cationic occupancy of constituent elements in the surface film, the atomic occupancy of constituent elements under the surface film and its thicknesses after air exposure and immersion for $168 \mathrm{~h}$ in SBF solutions after mechanical polishing, respectively. In figure $3 \mathrm{a}$, the atmospheric oxidation film on the metallic glass 


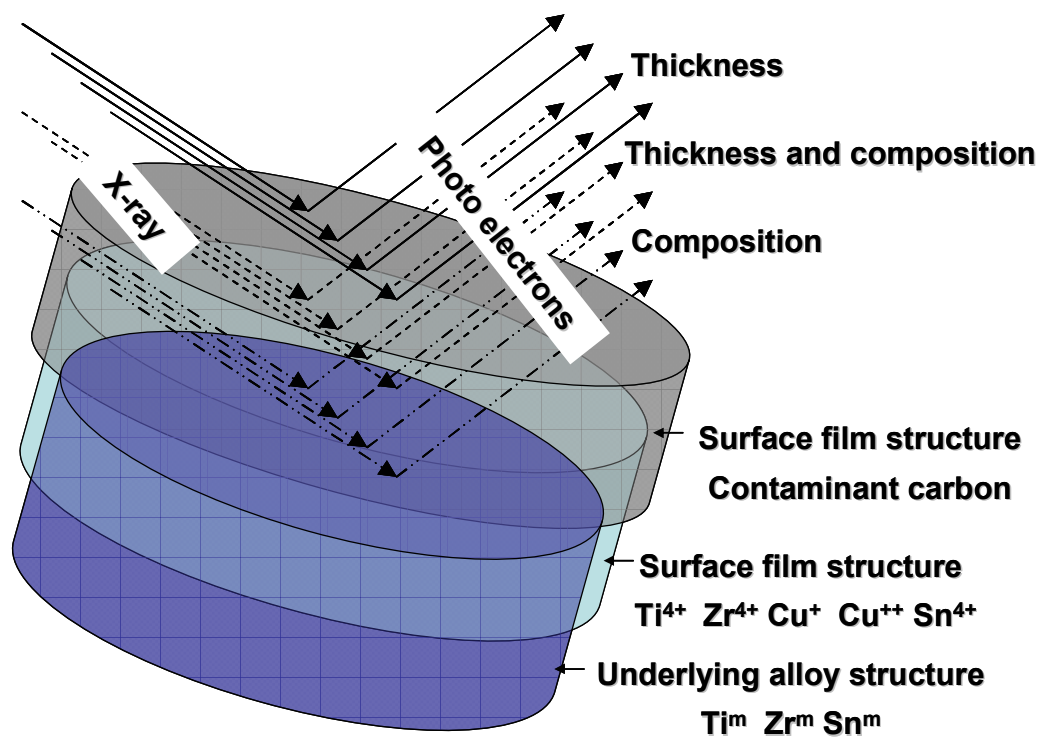

Surface structure of specimen

Fig. 2. The compositions of surface films measured by XPS for the $\mathrm{Ti}_{45} \mathrm{Zr}_{10} \mathrm{Pd}_{10} \mathrm{Cu}_{31} \mathrm{Sn}_{4}$ alloy

after mechanical polishing is enriched in $\mathrm{Ti}$ and $\mathrm{Zr}$ and depleted in $\mathrm{Cu}$. The phenomena can be related to the oxidation of $\mathrm{Ti}$ and $\mathrm{Zr}$. These elements have a strong tendency to oxidize and creating high compact semiconductivity-oxide film layer in air. Meanwhile, noble metal Pd element dose not form a corroded product. In case of the underlying surface, as shown in figure $3 \mathrm{~b}$, it is enriched in $\mathrm{Pd}$ and $\mathrm{Cu}$. Sn content is also slightly higher than in the top layer. Meanwhile, Ti and $\mathrm{Zr}$ elements could not be observed in the underlying part. Consequently, after mechanical polishing and air exposure the $\mathrm{Ti}_{45} \mathrm{Zr}_{10} \mathrm{Pd}_{10} \mathrm{Cu}_{31} \mathrm{Sn}_{4}$ glassy alloy has an oxide surface film enriched in $\mathrm{Ti}$ and $\mathrm{Zr}$, while $\mathrm{Pd}$ and $\mathrm{Cu}$ elements occupied the underlying part.

When the specimen is immersed in PBS(-) solution (table 1), the concentration of $\mathrm{Ti}$, $\mathrm{Zr}$ and $\mathrm{Sn}$ cations in the surface film is higher than in the oxide film produced by air

(a) Cationic fractions in the surface film

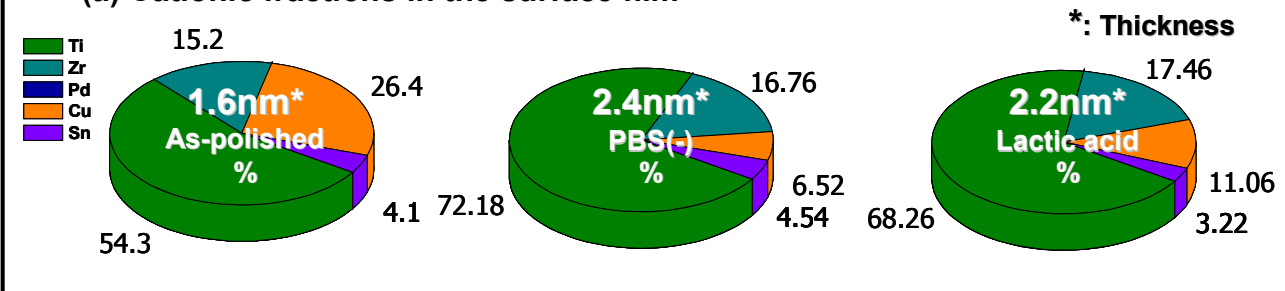

(b) Atomic fractions in the underlying alloy surface
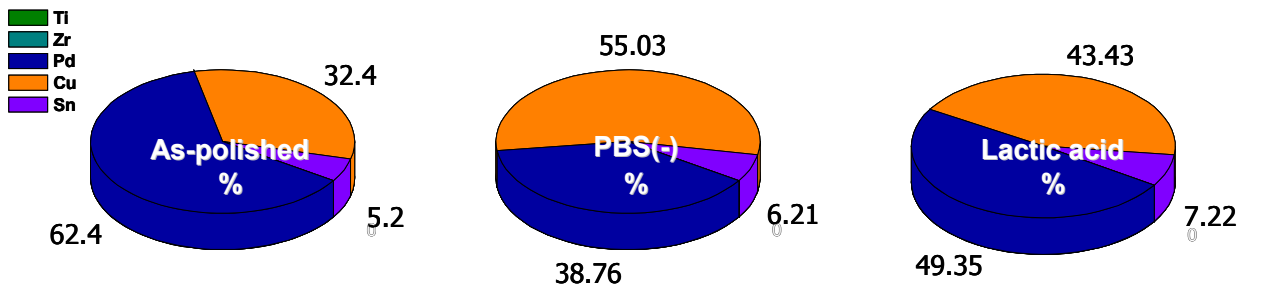

Fig. 3. The changes in (a) cationic fractions in the surface film and (b) atomic fractions in the underlying alloy surface for the as-cast $\mathrm{Ti}_{45} \mathrm{Zr}_{10} \mathrm{Pd}_{10} \mathrm{Cu}_{31} \mathrm{Sn}_{4}$ alloy exposed to air and those immersed in PBS(-) and $1 \mathrm{mass} \%$ lactic acid solutions at $310 \mathrm{~K}$ 
Table 1. Electrolytes for evaluation of biochemical stability

\begin{tabular}{|c|c|}
\hline $\begin{array}{l}\text { Component (DL-lactic acid) PH } 2.5 \\
\text { Wako pure chemical Industries, Ltd. }\end{array}$ & $g / L$ \\
\hline 2-Hydroxypropionic acid $\left[\mathrm{CH}_{3} \mathrm{CH}(\mathrm{OH}) \mathrm{COOH}\right]$ & 90.1 \\
\hline $\begin{array}{l}\text { Component ( PBS(-)) PH } 7.4 \\
\text { Cembrex }\end{array}$ & $g / L$ \\
\hline Potassium Chloride $[\mathrm{KCl}]$ & 0.2 \\
\hline Potassium Phosphate Monobasic $\left[\mathrm{KH}_{2} \mathrm{PO}_{4}\right]$ & 0.2 \\
\hline Sodium Chloride $[\mathrm{NaCl}]$ & 8.0 \\
\hline Sodium Phosphate Dibasic $\left[\mathrm{Na}_{2} \mathrm{HPO}_{4}\right]$ & 1.15 \\
\hline $\begin{array}{l}\text { Component (HBSS w/o Ca and Mg or Phenol red) PH } 7.4 \\
\text { ICN biomedicals }\end{array}$ & $g / L$ \\
\hline Potassium Chloride $[\mathrm{KCl}]$ & 0.4 \\
\hline Potassium Phosphate Monobasic $\left[\mathrm{KH}_{2} \mathrm{PO}_{4}\right]$ & 0.06 \\
\hline Sodium Chloride $[\mathrm{NaCl}]$ & 8.0 \\
\hline Sodium Hydrogen Phosphate Heptahydrate $\left[\mathrm{Na}_{2} \mathrm{HPO}_{4} \cdot 7 \mathrm{H}_{2} \mathrm{O}\right]$ & 0.09 \\
\hline Sodium bicarbonate $\left[\mathrm{NaHCO}_{3}\right]$ & 0.35 \\
\hline Glucose & 1.0 \\
\hline
\end{tabular}

oxidation. The corrosion rate of the specimen has an undetectable in PBS (-) solution for $168 \mathrm{~h}$. The surface film has had a cationic composition of $\mathrm{Ti}_{72.18} \mathrm{Zr}_{16.76} \mathrm{Cu}_{6.52} \mathrm{Sn}_{4.54}$ (as shown figure 3a) in PBS (-) solution, with the highest concentration Ti which could protect itself against corrosion (as shown figure $3 \mathrm{a}$ and $3 \mathrm{~b}$ ). On the other hand, $\mathrm{Pd}, \mathrm{Cu}$ and $\mathrm{Sn}$ contents are remarkably higher than at the underlying surface condition.

In addition, the specimen is also immersed in 1 mass \% Lactic acid solution (table 1) without chloride ions for $168 \mathrm{~h}$. The corrosion rate of the specimen also has an undetectable value as in case of PBS (-) solution. It could regard formed oxygen-bearing film by the auto-oxidation which became a good synthesizer for passivation. The surface film changed for protecting itself against corrosion in acid environment. The cationic composition is $\mathrm{Ti}_{68.26} \mathrm{Zr}_{17.46} \mathrm{Cu}_{11.06} \mathrm{Sn}_{3.22}$ (as shown figure 3a). $\mathrm{Zr}$ shows more sensitive reaction for the formation of surface oxide layer in lactic acid than $\mathrm{Ti}$. In case of the underlying surface, $\mathrm{Pd}$ content is the highest than at conditions owing to the cationic composition of $\mathrm{Pd}_{49.35} \mathrm{Cu}_{43.43} \mathrm{Sn}_{7.22}$ as shown Figure 3b. The results of the immersion test for $168 \mathrm{~h}$ in different solutions reveal that Ti-based glassy alloy has a good corrosion resistance by variation of the surface chemical composition.

We have also measured the corrosion rate for the Ti-based BMG each week during the 2 months immersion test. Metallic luster without pitting corrosion retained on their surfaces. The corrosion rate of the specimen was undetectable. It is indicated that the passivation film of Ti-based BMG defends the samples well PBS (-) solution and 1\% lactic acid solutions. As a result, it is understood that Ti-based BMG has a good corrosion resistance.

We also carried out evaluating for crevice corrosion test in PBS (-) and HBSS (Hanks balance salt solution: table 1) at the same conditions. This chemical evaluation is necessary for implantation in the oral cavity. In general, Crevice corrosion is caused by oxygen deficiency at small recesses, such as those found under the head of screws or inside of pores of porous surfaces. Natural convection of the bulk solution becomes restricted, and the supply of oxygen required maintaining passivation impaired. In the absence of oxygen, aggressive species such as chlorides ions concentrate and promote the crevice. The $\mathrm{Ti}_{45} \mathrm{Zr}_{10} \mathrm{Pd}_{10} \mathrm{Cu}_{31} \mathrm{Sn}_{4}$ metallic glass is not prone to crevice corrosion after immersed in PBS 
(-) and HBSS at $310 \mathrm{~K}$ during 720 hours. In this research, crevice corrosion was not observed in Ti-based glass alloys under SBF containing chlorides ions.

Finally, we have investigated the effects the metal ions from the $\mathrm{Ti}_{45} \mathrm{Zr}_{10} \mathrm{Pd}_{10} \mathrm{Cu}_{31} \mathrm{Sn}_{4}$ metallic glass. Protection of metallic implants by the passivated surface film is the most important property because of the human body liquids tries to dissolve the implant surface by chemical solubility, degradative enzyme, macrophage cell, etc. Inserted materials for biomaterials should not be dissolved by the organism or artful friction under any circumstance. Toxic reaction may occur in the neighborhood of the implant or in other oranges where they are caused by metabolism. Result for initial implantation of the $\mathrm{Ti}_{45} \mathrm{Zr}_{10} \mathrm{Pd}_{10} \mathrm{Cu}_{31} \mathrm{Sn}_{4}$ metallic glass in medium culture with human osteoblasts at $310 \mathrm{~K}$ for 8 days has been observed a good biocompatibility with Ti-based alloys in this study. These Ti-6Al-4V and Ti-45Ni alloys were introduced for relative valuation of biocompatibility as references because of being used biomedical materials. Biocompatibility of Ti-based metallic glass was confirmed that prominently-manifested necrosis of osteoblasts could not be detected by cell culture. It has an equally competent for osteoblasts as result of references. However, it is seems to be that the stabilized surface film of the $\mathrm{Ti}_{45} \mathrm{Zr}_{10} \mathrm{Pd}_{10} \mathrm{Cu}_{31} \mathrm{Sn}_{4}$ metallic glass inhibits biodegradation in the biological environment of the human body. It could be considered that the constituent surface films of this metallic glass in SBF solutions are enriched in $\mathrm{Ti}$ and $\mathrm{Zr}$. As a valuable result, $\mathrm{Cu}$ content in the surface of the $\mathrm{Ti}_{45} \mathrm{Zr}_{10} \mathrm{Pd}_{10} \mathrm{Cu}_{31} \mathrm{Sn}_{4}$ metallic glass is not high enough to cause cytotoxity by biochemical corrosion $^{(12)}$.

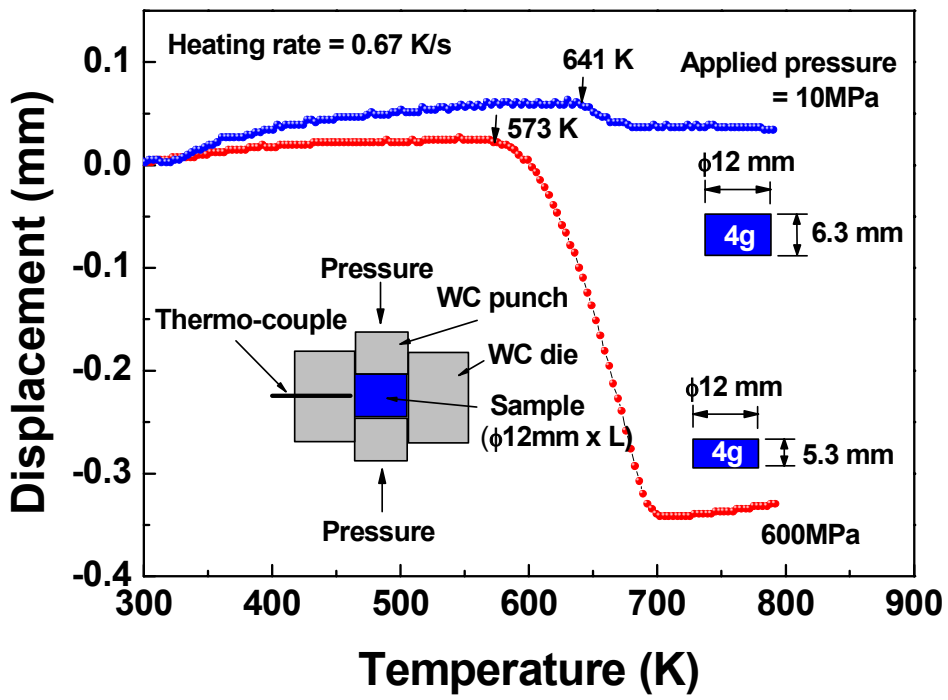

Fig. 4. TMA curves for the $\mathrm{Ti}_{45} \mathrm{Zr}_{10} \mathrm{Pd}_{10} \mathrm{Cu}_{31} \mathrm{Sn}_{4}$ metallic glassy powder with $10 \mathrm{MPa}$ and $600 \mathrm{MPa}$ for compressive stress at the heating rate of $0.67 \mathrm{~K} / \mathrm{s}$

$\mathrm{Ti}_{45} \mathrm{Zr}_{10} \mathrm{Pd}_{10} \mathrm{Cu}_{31} \mathrm{Sn}_{4}$ metallic glass has thermal properties ${ }^{(7)}$ as $\mathrm{T}_{\mathrm{g}}(681 \mathrm{~K}), \mathrm{T}_{\mathrm{x}}(737 \mathrm{~K})$ and $\Delta \mathrm{T}_{\mathrm{x}}\left(\mathrm{T}_{\mathrm{x}}-\mathrm{T}_{\mathrm{g}}=56 \mathrm{~K}\right)$. In this study, it has been attempted to evaluate for synthetic structure by flow-viscosity on spark plasma sintering technique process. Figure 4 explains to preparation for the consolidated samples of the $\mathrm{Ti}_{45} \mathrm{Zr}_{10} \mathrm{Pd}_{10} \mathrm{Cu}_{31} \mathrm{Sn}_{4}$ metallic glassy powder alloy and exploration for consolidation condition in this study. Thermal characteristics with different pressurization in consolidation process, metallic glass powders exhibit variation of initial flow-viscosity around $\mathrm{T}_{\mathrm{g}}(681 \mathrm{~K})$. Additional pressure effect could be contributed to expand glass transition region and accelerate metamorphosis by flow-viscosity. Figure $5 \mathrm{a}$ is well explained that consolidated specimens still have an amorphous structure by detected a broad peak in XRD patterns and facture surface(fig. 5b) reveal that liquidity combine with other particles at glass transition temperature in TMA traces. In case of excess crystallization temperature for $737 \mathrm{~K}$, consolidate sample exhibits mixing phase, amorphous phase and $\mathrm{Ti} 2 \mathrm{Cu}$ phase, by XRD detection. Experimental results 

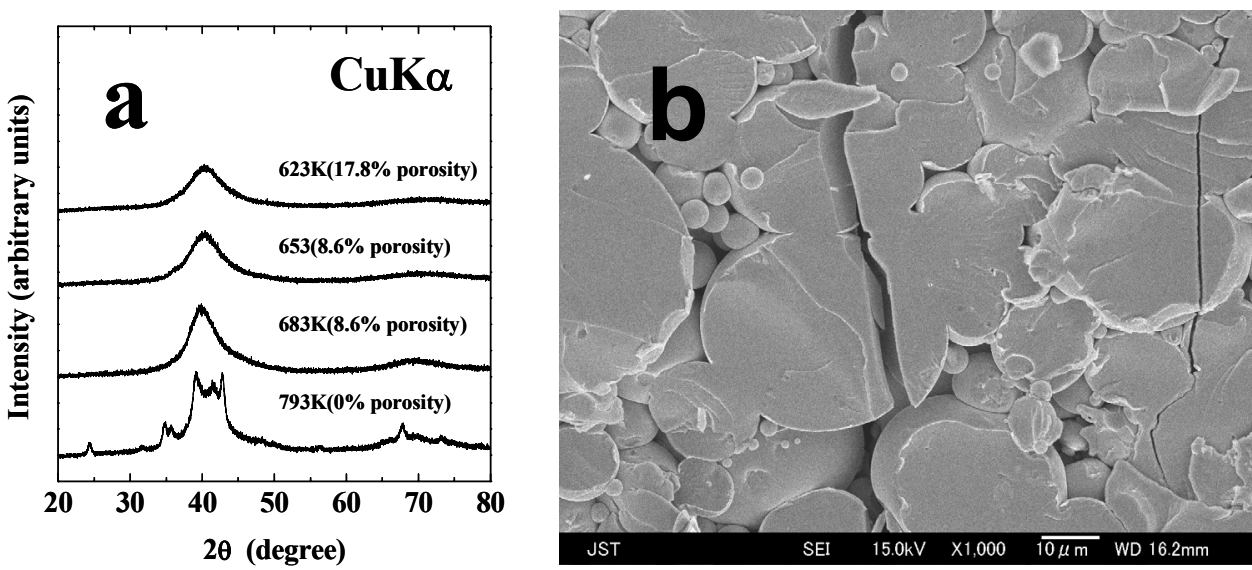

Fig. 5. XRD patterns for various consolidation temperatures (a) and morphology for fracture surface of consolidated sample at $623 \mathrm{~K}$ (b)

revealed high consolidation ability within flow viscosity region which has compatible thermal stability with those of $\mathrm{Zr}$ - or Fe-based metallic glasses with wide supercooled liquid region. And it was confirmed that spark plasma sintering technique contributed forming process for Ti-based metallic glass powder and effectively created volume forming ability without any crystallization. According to the last report for $\mathrm{Ti}_{45} \mathrm{Zr}_{10} \mathrm{Pd}_{10} \mathrm{Cu}_{31} \mathrm{Sn}_{4}$ metallic glass, this metallic glass by copper mold casting technique has a critical bulk forming ability $4.0 \mathrm{~mm}$ in diameter by thermal stability and high glass forming ability, critical bulk forming ability $4.0 \mathrm{~mm}$ in diameter and high compressive strength for $1970 \mathrm{MPa}$. In case of mechanical property of solidified Ti-based metallic glass powder containing $8.6 \%$ for porosity, it has also good mechanical strength for $1490 \mathrm{MPa}$ in compressive test. Based on all results of this study, $\mathrm{Ti}_{45} \mathrm{Zr}_{10} \mathrm{Pd}_{10} \mathrm{Cu}_{31} \mathrm{Sn}_{4}$ metallic glass shows chemical stability, mechanical property as well as good workability under the pressurization with rheological changes by flow-viscosity.

\section{Conclusion}

We have carried out the characterization of the surface structures, cell reaction and workability by spark plasma sintering technique for $\mathrm{Ni}$-free Ti-based metallic glass in this study. The $\mathrm{Ti}_{45} \mathrm{Zr}_{10} \mathrm{Pd}_{10} \mathrm{Cu}_{31} \mathrm{Sn}_{4}$ metallic glass exhibits a high potentiality to be applied as dental implants which exhibits good corrosion resistance from demonstrated results by surface condition in various electrolytes for biomaterials test and good biocompatibility in osteoblast culture test. In addition, we also have successfully fabricated to the consolidated Ti-based metallic glass with large scale by spark plasma sintering technique. The fabricated Ti-based glassy alloy by above technique exhibits an implantable biomaterials potentiality to be applied for structural materials.

\section{Acknowledgements}

This work has been supported by Highly-functional Interface Science: Innovation of Biomaterials with Highly-functional Interface to Host and Parasite (Tohoku University Institute for Materials Research and Graduate School of Dentistry, Kyushu University Research Institute for Applied Mechanics).

\section{References}

(1) Niinomi M., Hanawa T., Narushima T., Japanese research and development on metallic biomedical, dental, and healthcare materials, JOM, Vol. 52 (2005), pp.18-24

(2) Oak J. -J., Inoue A., Attempt to develop Ti-based amorphous alloys for biomaterials, Materials Science \& Engineering A; Vol. 449 (2007), pp. 220-224

(3) Suryanarayana C, Inoue A, Masumoto T., Transformation studies and mechanical properties 
of melt-quenched amorphous titanium-silicon alloys, Journal of materials Science, Vol. 15 (1980); pp. 1993-2000

(4) Inoue A, Masumoto T, Okamoto S, Takahashi Y., The stress effect on the superconducting properties of an amorphous $\mathrm{Ti}_{55} \mathrm{Nb}_{30} \mathrm{Si}_{15}$ alloy, Scripta Metallurgica, Vol.16 (1982), pp. 1141-1144

(5) Naka M, Hashimoto K and Masumoto T., Corrosion behavior of amorphous and crystalline Cu50Ti50 and Cu50Zr50 alloys, Journal of Non-Crystalline Solids, Vol. 30 (1978); pp. 29-36

(6) Inoue A., Stabilization of metallic supercooled liquid and bulk amorphous alloys. Acta Materialia, Vol.48 (2000); pp. 279-306

(7) Oak J. -J., Louzgine Louzgin DV, Inoue A., Fabrication of Ni-free Ti-based BMG alloy having potential for application as biomaterial and investigation of its mechanical properties, corrosion and crystallization behavior, Journal of Materials Research, Vol.22 (2007); pp. 1346-1353

(8) Calin M, Zhang LC and Eckert J., Tailoring of microstructure and mechanical properties of a Ti-based bulk metallic glass-forming alloy,, Scripta Materialia, Vol.57 (2007); pp. 1101-1104

(9) Qiu CL, Chen Q, Liu L, Chan KC, Zhou JX, Chen PP and Zhang SM., A novel Ni-free Zr-based bulk metallic glass with enhanced plasticity and good biocompatibility, Scripta Materialia, Vol.55 (2006); pp. 605-608

(10) Asami K, Hashimoto K., An XPS study of the surfaces on Fe-Cr, Fe-Co and Fe-Ni alloys after mechanical polishing, Corrosion Science, Vol.24 (1984); pp. 83-97

(11) Asami K, Hashimoto K, Shimodaira S., XPS determination of compositions of alloy surfaces and surface oxides on mechanically polished iron-chromium alloys, Corrosion Science, Vol.17 (1977); pp. 713-723

(12) Hiromoto S, Asami K, Tsai AP, Hanawa T., Surface Characterization of Amorphous Zr-Al-(Ni, Cu) Alloys Immersed in Cell-Culture Medium, Materials Transactions, Vol. 43 (2002); pp. 261-266 